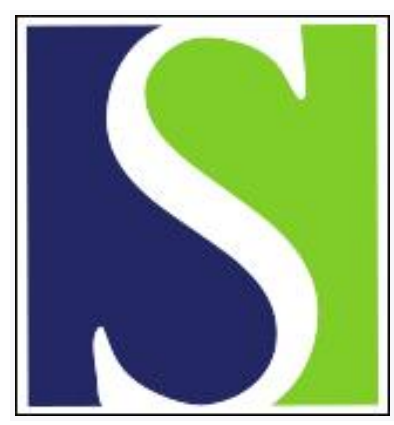

Scand J Work Environ Health 2008;34(5):374-380

https://doi.org/10.5271/sjweh.1277

Published online: 14 Oct 2008, Issue date: 00 Oct 2008

Follow-up study of musculoskeletal disorders 20 months after the introduction of a mouse-based computer system by Arvidsson I, Axmon A, Skerfving S

Affiliation: Division of Occupational and Environmental Medicine, Lund University Hospital, SE-211 85 Lund, Sweden. inger.arvidsson@med.lu.se

Refers to the following texts of the Journal: 1998;24(5):418-424 2005;31(6):438-449 2001;27 suppl 1:1-102 2002;28(4):215-221

Key terms: air-traffic control; complaint; computer system; diagnosis; follow-up study; mouse-based computer system; MSD; musculoskeletal disorder; physical examination; prospective study

This article in PubMed: www.ncbi.nlm.nih.gov/pubmed/18853068 


\title{
Follow-up study of musculoskeletal disorders 20 months after the introduction of a mouse-based computer system
}

\author{
by Inger Arvidsson, PhD, ${ }^{1}$ Anna Axmon, PhD, ${ }^{1}$ Staffan Skerfving, $M{ }^{1}$
}

\begin{abstract}
Arvidsson I, Axmon A, Skerfving S. Follow-up study of musculoskeletal disorders 20 months after the introduction of a mouse-based computer system. Scand J Work Environ Health 2008;34(5):374-380.
\end{abstract}

\begin{abstract}
Objectives This study attempted to determine whether musculoskeletal health is influenced by mouse-intensive computer work.

Methods The neck-upper limbs of 148 air-traffic controllers (71 women, 77 men) with demanding computer work were examined before (baseline) and a median of 20 months after (follow-up) a change from varied computer work to a mouse-based system, causing a significant change in the physical exposure of the workers (eg, lower variation of work postures and less rest in the forearm extensor muscles, as assessed by technical measurements). Complaints (according to a Nordic questionnaire), diagnoses (standardized physical examination), and psychosocial work environment (Copenhagen Psychosocial Questionnaire) were recorded.

Results The air traffic controllers had consistently higher prevalences of disorders in the elbows-hands in the follow-up than at the baseline (complaints $30 \%$ versus $18 \%, \mathrm{P}=0.03$; diagnoses $10 \%$ versus $3.4 \%, \mathrm{P}=0.02$ ). The predominance of right-arm disorders was more pronounced in the follow-up than at the baseline. For the neckshoulders-upper back, there was no consistent difference between the baseline and follow-up values; disorders increased significantly among the "young" controllers ( $\leq 37$ years), but not among the "older" ones. Perceived decision latitude decreased, while social support increased, but these changes did not explain the disorders that appeared in the elbows-hands.

Conclusions Intensive mouse-based computer work, with constrained posture and little rest in the forearm muscles, was associated with an increased risk of disorders in the elbows-hands. This finding should be considered for similar technological developments in other settings.
\end{abstract}

Key terms air-traffic control; complaint; diagnosis; physical examination; prospective study.

Over the past 20 years, information technology has gone through radical changes that have strongly influenced worklife, as well as the whole of society. In most occupational groups, computers are now necessary work tools. In Sweden in 2005, 69\% of the workforce used computers in their daily work (1). Computers are also used extensively by children and students.

Several studies claim that computer-intensive work is associated with an increased risk of musculoskeletal disorders in the neck-upper limbs $(2,3)$. Workstation design and computer equipment influence the risk (4, 5). Especially the input device may play an important role, because of its effects on posture, movements, and muscular load $(6,7)$. New computer systems imply a considerable increase in mouse use. Compared with the keyboard, mouse operations lead to higher demands on eye-hand coordination and a stronger visual focus on the screen (8), which, in turn, may imply more constrained postures (9). In addition, there is a higher load on the forearm muscles (9).

In a recent review (10), it was concluded that there was moderate evidence for an association between the duration of mouse use and disorders in the hand-arm region. However, the information on the use of a computer and mouse was mostly based on self-reports, which may overestimate the duration of use (11). Moreover, since most operators use both a keyboard and a computer mouse, it was difficult to separate the exposures.

Air-traffic control work is based almost entirely on information technology. In March 2005, there was a momentary change in the computer system used by Swedish air-traffic controllers. While the old system was managed with a keyboard, a trackball, and manual writing, the new one was characterized by intensive mouse use. Technical measurements showed that the new system was associated with significantly lower 
movement velocities, less posture variation for all of the measured body segments, higher muscular activity, and less rest in the right forearm extensor muscles in the mouse-operating arm (9). Before the change, the air-traffic controllers had fairly high prevalences of disorders in the neck-shoulders-upper back, while disorders in the arm-hand region were less prevalent (12). The psychosocial work environment was characterized by high demands, low decision latitude, high social support, and low stress (13).

The aim of our present study was to determine whether musculoskeletal health among air-traffic controllers is influenced by a change from varied computer work to mouse-intensive computer work.

\section{Study population and methods}

\section{Air-traffic control work}

The air-traffic control centers in Malmö and Stockholm consist of 45 identical workstations (9). The controllers were scheduled to work uninterruptedly in cycles of 1.5 hours "on-line", followed by a break of 45 minutes, in total about 5 hours of computer work per day. In addition, the controllers used personal computers during their breaks for other occupational tasks, such as e-mail communication, averaging about 1 hour (range 0.5-3 hours) per day.

In the old system (9), each air-traffic controller was responsible for one sector of the air space. Incoming aircrafts were announced on paper strips. The controller sat in front of a radar screen (diameter $500 \mathrm{~mm}$ ), also using a keyboard and a trackball. Changes in the height, speed, or direction of aircraft were noted on the paper strips, by manual writing.

In the new system (9), each sector was controlled from two workstations, and the controllers worked pairwise. Each controller had a large square video display unit (VDU) (size $505 \times 505 \mathrm{~mm}$ ), a regular computer screen, a keyboard, and an ordinary computer mouse. Most of the information was given on the large VDU. The mouse was used in almost all commands during work, and the keyboard was used only to a minor extent.

\section{Baseline}

At the baseline (examination I, figure 1), all currently employed 187 certified air-traffic controllers (90 women and 97 men; participation rate 100\%) were examined (12). The median age and time of employment were 37 (range 24-58) years and 11 (range 0-34) years, respectively. The inclusion criteria were operative air-traffic control work $\geq 20$ hours/week, for at least 3 months. At the baseline, 128 persons (68\%) worked full-time (30-40 hours/week), and 59 persons (32\%) worked part-time as controllers (20 hours/week) and part-time performing administrative worktasks.

\section{Prospective group}

The follow-up (examination II) was made at a median of 4.7 (range 2.9-5.3) years after the baseline examination (figure 1). The follow-up was carried out 2 years later than planned due to an unexpected delay in the introduction of the new system. Altogether 148 (79\%) of the 187 persons who were examined in the baseline examination, 71 women and 77 men, were examined. The median age and time of employment at the time of the follow-up were 42 (range 27-60) years and 16 (range 3-37) years, respectively. The inclusion criteria were the same as in examination I. The controllers had worked in the new system for a median of 20 (range 3-27) months, preceded by 1.5-2 months of education in simulated airtraffic control. The proportion of full-time controllers was $78 \%$, and $22 \%$ did part-time administrative work. The right hand was used for mouse operations by all but two participants, in spite of the fact that $12(8 \%)$ were left-handed.

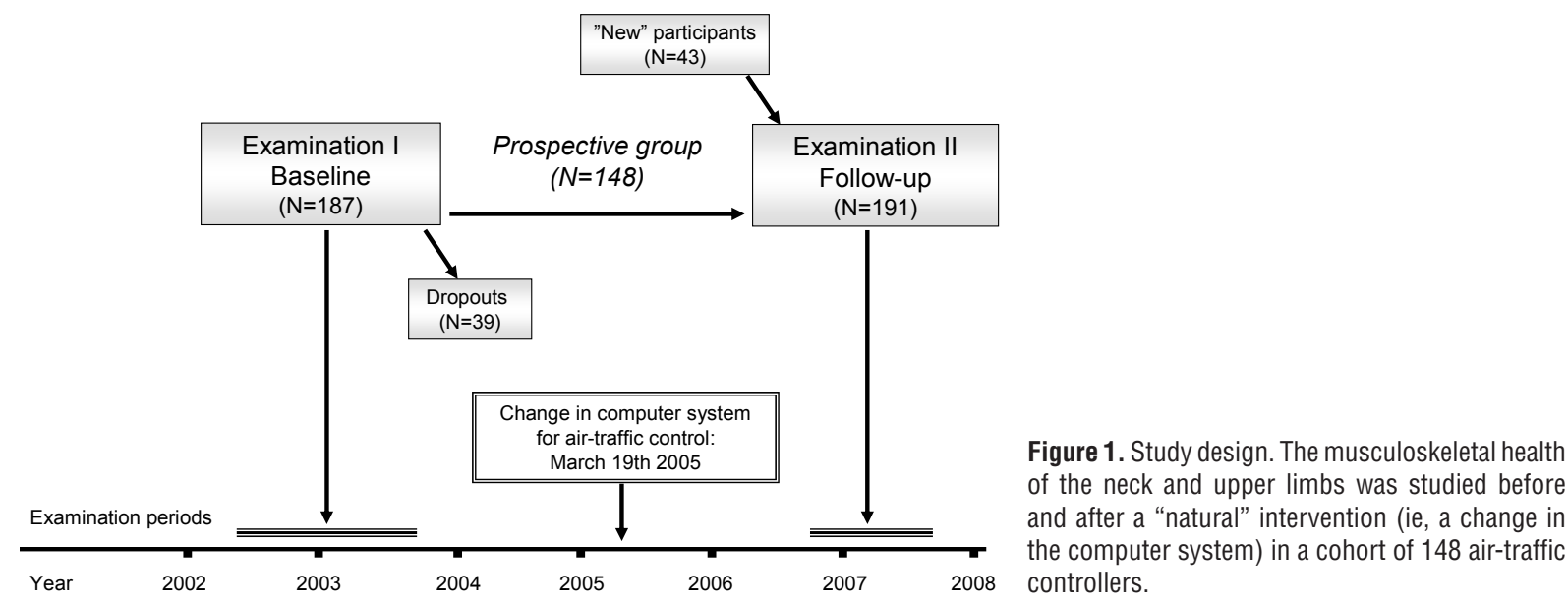




\section{Dropouts}

Of the 187 participants in examination I, 39 (20 men and 19 women) did not participate in examination II because of retirement (4 men), child care (7 women), change of worktasks ( 8 men and 8 women), migration ( 7 men and 3 women), or university studies (1 man and 1 woman). The median age and time of employment at baseline were 36 (range 26-58) years and 10 (range 1-34) years, respectively. Among the dropouts, 36 were reached for an interview. Regarding the musculoskeletal health at baseline, there was no significant difference between the dropouts and those who participated in the followup (methods described later): elbow-hand complaints $8 \%$ versus $18 \%$ [prevalence odds ratio (POR) $0.3,95 \%$ confidence interval (95\% CI) 0.1-1.2]; age-adjusted diagnoses $0 \%$ versus 3\%, neck-shoulder-upper-back complaints $46 \%$ versus $41 \%$ (POR $1.2,95 \%$ CI $0.6-2.5$; diagnoses $18 \%$ versus $18 \%$ (POR 1.0, 95\% CI $0.4-2.5$ ). None of the dropouts reported that they had left air-traffic control work because of musculoskeletal pain.

\section{"New" participants}

In addition, 43 "new" air-traffic controllers (15 women and $28 \mathrm{men}$ ), who fulfilled the inclusion criteria, participated in examination II. The median age and time of employment were 33 (range 26-54) years and 6 (range 2-26) years, respectively. Among these workers, 23 started their employment in the old system after examination I, and 10 started work after the change in the system. The remaining 20 "new" controllers were off duty at the time of the baseline examination.

\section{Interview}

In examinations I and II, the participants were asked about musculoskeletal complaints during the last 7 days, according to the Standardized Nordic Questionnaire (14) and the duration of the complaints. Furthermore, they were asked if they believed that the complaints were work-related. The participants were also asked about their family situation and their responsibility for children, their sports activities, and their smoking. Data on computer use during their spare time was collected in categories as follows: (i) no computer use, (ii) $<2$ hours/ week, (iii) 2-5 hours/week, (iv) $>5$ hours/week. In examination II, the controllers were asked their opinion about the new air-traffic control system per se (usability) and about ergonomic factors at the new workstations.

\section{Physical examination}

A standardized physical examination (15) of the neck, shoulders, upper back, elbows, wrists, and hands was performed in both examinations by the same physical therapist. Diagnoses were made by the examiner according to predefined criteria for findings. Compared with the original method (15), the diagnoses trapezius myalgia [current pain from the neck and tender and restricted trapezius muscle(s)] and de Quervain's disease (wrist pain, palpable tenderness of the tendons of the first dorsal compartment of the wrist, positive Finkelstein's test) were added. After the baseline examination, the criteria for some of the elbow-hand diagnoses were revised to increase sensitivity $(16,17)$. The same protocol was used in both examinations, and all of the findings have been saved. Hence the prevalences of the elbow-hand diagnoses reported at baseline (12) have been recalculated in this study to make the two examinations comparable.

\section{Psychosocial work environment}

A questionnaire on psychosocial work conditions (Copenhagen Psychosocial Questionnaire (COPSOQ) (18) was administered to each participant immediately after the physical examination. A subset of 16 dimensions (with a total of 75 questions) was chosen to represent four different areas: demands, decision latitude, support, and stress (12). All of the questions were answered on a 5-point scale $(0,25,50,75$, or 100 points). For each participant, the dimension score was calculated as the mean of the included questions. Furthermore, the area scores were calculated as the mean of the included dimensions. In the prospective group, the questionnaire was answered at both examinations by 137 participants (participation rate 93\%).

\section{Statistical methods}

The complaints (total and work-related) and diagnoses in the prospective group at baseline and follow-up were compared by McNemar's test. The same method was used to compare complaints and diagnoses between the right and left arms.

To estimate the differences between independent groups (the total group of 187 controllers at examination I compared with the 43 who were examined only in examination II, dropouts compared with the prospective group at baseline, and full-time controllers compared with part-time controllers), the prevalence odds ratio (POR) with the $95 \%$ confidence interval $(95 \% \mathrm{CI})$ was calculated, using the logistic regression for complaints and diagnoses (adjusted for age).

To assess possible confounding, we analyzed the differences between the baseline and follow-up results of the COPSOQ scores and nonoccupational factors (decrease, no change, increase) using the Wilcoxon matched-pairs signed rank test. Then the controllers were stratified into the following four groups as regards 
complaints and diagnoses: (i) healthy in both examinations (healthy/healthy), (ii) new cases at follow-up (healthy/case), (iii) cases at baseline and healthy at follow-up (case/healthy), and (iv) cases in both examinations (case/case). Differences in possible confounders between these groups were assessed using the KruskalWallis test for continuous variables (actual difference in psychosocial scores) and the chi-square test for categorical variables (nonoccupational factors). The investigated possible confounders were demand, decision latitude, support, stress, computer use during leisure time, number of children at home, sports activities, and smoking. Statistical significance was taken as $\mathrm{P}<0.05$.

\section{Results}

\section{Musculoskeletal disorders in the prospective group}

For the elbows-hands, the air-traffic controllers had significantly higher prevalences of complaints and diagnoses at the follow-up, compared with the baseline values (table 1). In addition, the prevalence of work-related complaints from the elbows-hands the last year had increased from $16 \%$ to $40 \%$ ( $\mathrm{P}<0.001$, not in table).

For the neck-shoulders-upper back, there were no statistically significant differences in the complaints and diagnoses (table 1) between the two examinations. Furthermore, there was no significant change in the prevalences of work-related complaints the last year $(45 \%$ at the baseline versus $50 \%$ at the follow-up, $\mathrm{P}=0.37$ ).

However, the tendencies varied between the age stratums. The prevalence of diagnoses among the "young" participants ( $\leq 37$ years, median age at baseline) increased in both the elbows-hands ( $0 \%$ at baseline versus $5.6 \%$ at follow-up, data not in table) and the neck-shoulders $(8.5 \%$ versus $30 \%, \mathrm{P}<0.001)$. Among the "older" controllers ( $>37$ years), it numerically increased for the elbows-hands $(6.6 \%$ versus $14.5 \%, \mathrm{P}=0.15)$ but decreased for the neck-shoulders (26\% versus $16 \%$, $\mathrm{P}=0.13$ ). Elbow-hand complaints increased numerically among both the "young" (10\% versus $23 \%, \mathrm{P}=0.08)$ and "older" ( $26 \%$ versus $36 \%, \mathrm{P}=0.24)$ workers, while neck-shoulder-upper-back complaints were similar in both age groups and at both examinations.

At baseline, there were no significant differences in the prevalences of disorders between the full-time and part-time controllers. However, at the follow-up, those who worked full-time had significantly more complaints in the elbows-hands (35\% versus $12 \%$, POR $4.3,95 \%$ CI 1.3-13, age-adjusted; data not shown) and the neck-shoulders-upper back (54\% versus $27 \%$, POR $3.1,95 \%$ CI 1.3-7.2), as compared with the values of the part-time operators. For diagnoses, there were no such differences.

\section{Right arm versus left arm}

The prevalences of both complaints and diagnoses were significantly higher for the right arm (shoulder, elbow and hand combined) than the left in the followup examination (complaints: $43 \%$ versus $33 \%, \mathrm{P}=0.02$; diagnoses: $16 \%$ versus $9.5 \%, \mathrm{P}=0.04$ ), but not in the baseline examination (complaints: $33 \%$ versus $27 \%$, $\mathrm{P}=0.15$; diagnoses: $8.8 \%$ versus $6.8 \%, \mathrm{P}=0.61$ ).

\section{"New" participants versus total group at baseline}

For the elbows-hands, the 43 "new" participants in examination II had a significantly higher prevalence of complaints than the original baseline group, which included 187 participants (complaints: $23 \%$ versus $16 \%$, POR 2.4, 95\% CI 1.0-5.9, adjusted for gender and age). For the elbow-hand diagnoses, there was no significant difference ( $0 \%$ versus $2.7 \%$ ). For the neck-shoulders-upper back, there were no significant differences between the groups (complaints: $44 \%$ versus $42 \%$, POR $1.3,95 \%$ CI $0.6-2.6$; diagnoses: $21 \%$ versus $18 \%$; POR $1.8,95 \%$ CI $0.7-4.3$, adjusted for gender and age).

\section{Psychosocial work environment}

In some aspects, the perception of the psychosocial work environment changed between the baseline and followup examinations. The controllers in the prospective group reported significantly lower decision latitude and higher support at the time of the follow-up (table 2).

The change in decision latitude did not differ significantly between the four groups of controllers ("healthy/ healthy", "healthy/case", "case/healthy", and "case/ case" at baseline/follow-up) as regards complaints and diagnoses in the elbows-hands, as well as in the neckshoulders-upper back.

Table 1. Prevalences (\%) of musculoskeletal disorders in the elbows-hands and neck-shoulders-upper back in the prospective group, including 148 air-traffic controllers $\left(71^{\mathrm{a}}\right.$ women and 77 men) in the baseline and follow-up examinations.

\begin{tabular}{|c|c|c|c|c|c|c|}
\hline \multirow[t]{2}{*}{ Body region } & \multicolumn{3}{|c|}{ Complaints } & \multicolumn{3}{|c|}{ Diagnoses } \\
\hline & \multicolumn{3}{|c|}{ Baseline Follow-up P-value ${ }^{b}$} & \multicolumn{3}{|c|}{ Baseline Follow-up P-value ${ }^{b}$} \\
\hline \multicolumn{7}{|c|}{ Elbows-hands } \\
\hline Women & 18 & 32 & 0.10 & 4.3 & 11 & 0.12 \\
\hline Men & 18 & 27 & 0.25 & 2.6 & 9.1 & 0.18 \\
\hline All & 18 & 30 & 0.03 & 3.4 & 10 & 0.02 \\
\hline \multicolumn{7}{|c|}{ Neck-shoulders-upper back } \\
\hline Women & 52 & 63 & 0.17 & 24 & 34 & 0.21 \\
\hline Men & 31 & 34 & 0.84 & 12 & 12 & 1.00 \\
\hline All & 41 & 48 & 0.20 & 18 & 22 & 0.34 \\
\hline
\end{tabular}

a One woman did not participate in the second physical examination, and only data on complaints are available for her.

b McNemar test for differences between the baseline and follow-up values. 
Table 2. Scores on the Copenhagen Psychosocial Questionnaire scales (0-100 points) for the 137 air-traffic controllers in the prospective group, in the baseline and follow-up examinations.

\begin{tabular}{lcccccc}
\hline Area & \multicolumn{5}{c}{ Scores } \\
\cline { 2 - 3 } & \multicolumn{2}{c}{ Baseline } & & \multicolumn{2}{c}{ Follow-up } & P-value \\
\cline { 2 - 3 } \cline { 5 - 6 } & Mean & SD & & Mean & SD & \\
\hline Demands & 49 & 9 & & 50 & 8 & 0.17 \\
Decision latitude & 57 & 9 & & 53 & 9 & $<0.001$ \\
Support & 61 & 9 & & 65 & 9 & $<0.001$ \\
Stress & 14 & 10 & & 14 & 10 & 0.86 \\
\hline
\end{tabular}

a Wilcoxon matched-pairs signed ranks test for the difference between the baseline and follow-up values.

\section{Nonoccupational factors}

Computer use outside work increased between the baseline and follow-up examinations (eg, $\geq 2$ hours/week: $58 \%$ versus $75 \%, \mathrm{P}<0.001$ ), while none of the other nonoccupational factors changed statistically significantly (data not shown).

There was no statistically significant difference in computer use during leisure time between the four groups of controllers as regards complaints and diagnoses in the neck-shoulders-upper back and complaints in the elbows-hands, while for the elbow-hand diagnoses, there was a difference close to significant. However, the two groups of cases ("healthy/case" and "case/case") were the ones that showed the least increase in computer use outside work at the time of the follow-up examination.

\section{Discussion}

After the introduction of a mouse-based computer system, with a significant change in the physical workload, the controllers had consistently higher prevalences of complaints and diagnoses concerning the elbow-hands. Disorders in the neck-shoulders-upper back did not differ significantly between the two examinations. In addition, the controllers reported lower decision latitude and higher social support, but these changes did not explain the elbow-hand disorders.

\section{Methodological issues}

A limitation of this study was the lack of a reference group. However, it was very hard to find a sufficiently large group of computer operators who did not use a computer mouse and who had the same socioeconomic status. However, some support may be obtained from the dropouts and the "new" participants. Thus among the 18 dropouts, who never worked in the new system, the prevalence of elbow-hand complaints (reported in the follow-up dropout interview) was $17 \%$, versus $30 \%$ in the prospective group at follow-up. This finding may indicate a lower risk. The group of "new" participants was heterogeneous, since many of them had been working also in the old system. Still, they had significantly more elbow-hand complaints in examination II than the original baseline group in examination I, while no such difference was found for the neck-shoulders-upper back.

The prevalences of musculoskeletal disorders increase with age in the general population (19). During the study period, the air-traffic controllers grew somewhat older. This occurrence may explain some of the increase in elbow and hand disorders, but probably only a fraction. Importantly, the increase in disorders was more pronounced among the "young" participants. We tried to predict the age effects, but, due to the small size of the cohort and few cases, the model was not stable.

Out of the potential confounders investigated, decision latitude, support, and computer use outside work were the only factors for which a change was observed during the study period. The increase in support at follow-up was not considered to be a confounder of the physical workload. Furthermore, the four groups ("healthy/healthy", "healthy/case", "case/healthy", "case/case") did not differ with respect to decision latitude, and the increase in computer use outside work tended to be negatively associated with elbow-hand diagnoses. Hence these time-related changes should not have influenced the conclusions.

The participation rate in the follow-up examination was good $(79 \%)$. The musculoskeletal health of the dropouts at baseline was similar to that of the prospective group, and none had left the operator work due to musculoskeletal problems. Hence there is no reason to suspect that selection explained the increased frequencies of disorders in the elbows-hands at follow-up.

The increased load on the forearm extensor muscles was known by the examiner (9). Therefore, the possibility of an observer bias must be considered. However, the standardized physical examination followed a very strict protocol, with a good interexaminer reproducibility (20). Hence observer bias was probably not a major source of bias. Moreover, the air-traffic controllers may have been influenced by public media attention on the adverse health effects of mouse use and by a report on the physical exposures in the new system (9). This situation might have influenced the complaints to some extent, but was less likely to have affected the results of the physical examination.

It could be argued that the exposure to the old system prevailed for an average of 2 years after the baseline examination (due to the delay in the introduction of the new system) and that some of the disorders recorded 
in the follow-up examination may have been due to the extended worktime in the old system. However, the prevalences of elbow and hand disorders were low in the first examination, despite work for 12 years (median time of employment) in the old system. Furthermore, air-traffic controllers with elbow or hand disorders in the follow-up examination reported that complaints had started after the change in the system, while disorders of the neck-shoulders-upper back had lasted for a longer time. Obviously, the exposure time in the new system was long enough to cause problems in the elbows and hands. However, if there were participants with temporary disorders caused by exertion due to their initial inexperience, they may have already recovered.

We have detailed information about the physical workload involved in both systems (9). Admittedly, the technical measurements were made for only a fraction of the controllers $(\mathrm{N}=14)$, and in simulated work in the new system (9). On the other hand, we performed paired measurements of the two systems under very realistic conditions. Then the old and new systems differed widely as to, for example, wrist movement velocities (50 degrees/second versus 19 degrees/second, 90th percentile) and rest of the forearm extensor muscles (9\% versus $3.5 \%$ of time), indicating that the change of systems implied more constrained hand and forearm work (9). These measures in the new system are similar to those recorded in other mouse-intensive computer work (21). Furthermore, the duration of daily mouse use was assessed ( $\geq 5$ hours/day) on the basis of the strict schedule for work and breaks among the controllers. We do not have specific measurements of mouse activity (eg, clicking), which seems to be important (11). However, due to the character of the work, the operators had to be continuously prepared to make mouse commands, which also may involve attention-related activities of the forearm muscles (22).

\section{Musculoskeletal disorders}

The risk of disorders in the elbows and hands in mouseintensive computer work is in accordance with results from the review of IJmker et al (10). The present 7-day prevalences of complaints were similar to those reported by Jensen et al (23), while our diagnoses were more frequent than in the study by Funch Lassen et al (24), probably due to their more strict criteria. Most results on the consequences of mouse-intensive computer work come from northern Europe. This situation is probably not due to differences in hardware, job station design, or variation in worktask, but, instead, to the fact that only a few prospective studies have been conducted in this area (and none concerning air-traffic controllers).

A pathophysiological mechanism behind the elbow and hand disorders may be the sustained mouse-associated muscular activation (25). In addition, the amplified prevalence of disorders in the right arms at follow-up, as compared with the prevalences for the left hand, is probably associated with the mouse operations, since all but 2 of the 148 controllers operated the mouse with their right hand and muscular rest was lower in that arm than in the left one (9).

Contrary to the results for the elbows and hands, there were fewer consistent increases in disorders in the neck-shoulders-upper back, and this finding is also in accordance with earlier results (10). This difference may be due to the high muscular rest in the trapezius muscles in both systems (9). However, the higher prevalence of diagnoses in the neck-shoulders-upper back among the "young" operators, compared with among the "older" ones, was unexpected. The recovery in several "older" participants, observed at follow-up, may have been due to chance, possibly to treatments (eg, physical therapy) or because experienced participants with disorders adjust their work patterns.

\section{Perception of ergonomic and psychosocial factors}

It is unlikely that the increase in disorders was explained by exertion due to technical problems in the new computer system, since almost all of the controllers $(95 \%)$ were satisfied with the usability. However, many controllers were dissatisfied with ergonomic factors in the workplace and the fact that the mouse was used too much. Associations between such dissatisfaction and disorders have been found earlier (22).

The general psychosocial work environment was perceived to be good, when compared with the situation in a Danish reference population (18), although the air-traffic controllers, as in the baseline examination, reported high demands and low decision latitude (12, 18). In spite of this situation, the stress levels were low, possibly because of the good social support. One reason for the decrease in decision latitude in the follow-up may have been a shortage of staff, partly because, in the new system, the controllers worked two-by-two. On the other hand, this work scheme facilitated social communication during work, which may explain the improved social support.

\section{Concluding remarks}

The present new air-traffic control system is not unique; similar mouse-based technology has been-or will be-introduced worldwide. It is obvious that preventive measures should be implemented, such as other input devices (6), short keyboard commands instead of mouse ones, better software (7), and ergonomically more adequate, adjustable workstations. As mouse use is a hallmark for all kinds of modern information technology, 
we believe that our results have importance far beyond air-traffic control.

\section{Acknowledgments}

Financial support was provided by the Swedish Council for Work Life and Social Research, AFA Insurance, the Medical Faculty of the Lund University, and the County Councils of Southern Sweden.

Valuable assistance was provided by Ms Anita Olsson, and statistical advice was given by Professor Ulf Strömberg. The kind cooperation of the Swedish Board of Civil Aviation and the air-traffic controllers is acknowledged.

\section{References}

1. Statistics Sweden, Swedish Work Environment Authority. Arbetsmiljön [The work environment 2005]. Stockholm: Statistics Sweden, Swedish Work Environment Authority; 2006. Statistiska meddelande, AM 68 SM 0601. [English summary]

2. Gerr F, Marcus M, Ensor C, Kleinbaum D, Cohen S, Edwards A, et al. A prospective study of computer users, I: study design and incidence of musculoskeletal symptoms and disorders. Am J Ind Med. 2002;41:221-35.

3. Wahlström J. Ergonomics, musculoskeletal disorders and computer work. Occup Med. 2005;55:168-76.

4. Rempel DM, Krause N, Goldberg R, Benner D, Hudes M, Goldner GU. A randomised controlled trial evaluating the effects of two workstation interventions on upper body pain and incident musculoskeletal disorders among computer operators. Occup Environ Med. 2006;63:300-6.

5. Korhonen T, Ketola R, Toivonen R, Luukkonen R, Häkkänen M, Viikari-Juntura E. Work related and individual predictors for incident neck pain among office employees working with video display units. Occup Environ Med. 2003;60:475-82.

6. Karlqvist L, Bernmark E, Ekenvall L, Hagberg M, Isaksson A, Rostö T. Computer mouse and track-ball operation: similarities and differences in posture, muscular load and perceived exertion. Int J Ind Ergon. 1999;23:157-69.

7. Unge Byström J, Hansson GÅ, Rylander L, Ohlsson K, Källrot G, Skerfving S. Physical workload on neck and upper limb using two CAD applications. Appl Ergon. 2002;33:63-74.

8. Laursen B, Jensen BR, Garde AH, Jørgensen AH. Effect of mental and physical demands on muscular activity during the use of a computer mouse and a keyboard. Scand J Work Environ Health. 2002;28(4):215-21.

9. Arvidsson I, Hansson GÅ, Mathiassen SE, Skerfving S. Changes in physical workload with implementation of mousebased information technology in air traffic control. Int J Ind Ergon. 2006;36:613-22.

10. IJmker S, Huysmans MA, Blatter BM, van der Beek AJ, van Mechelen W, Bongers PM. Should office workers spend fewer hours at their computer?: a systematic review of the literature. Occup Environ Med. 2007;64:211-22.

11. Hviid Andersen J, Harhoff M, Grimstrup S, Vilstrup I, Funch Lassen C, Brandt LPA, et al. Computer mouse use predicts acute pain but not prolonged pain in the neck and shoulder. Occup Environ Med. 2008;65:126-31.

12. Arvidsson I, Arvidsson M, Axmon A, Hansson G- $\AA$, Johansson CR, Skerfving S. Musculoskeletal disorders among female and male air traffic controllers performing identical and demanding computer work. Ergonomics. 2006;49:1052-67.

13. Arvidsson M. Organizational psychology and safety culture in air traffic control concerning organizational climate, situational leadership and psychosocial work environment [dissertation]. Lund (Sweden): Lund University; 2006.

14. Kuorinka I, Jonsson B, Kilbom Å, Vinterberg H, Andersson G, Jørgensen, K. Standardised Nordic questionnaires for the analysis of musculoskeletal symptoms. Appl Ergon. 1987; 18:233-7.

15. Ohlsson K, Attewell RG, Johnsson B, Ahlm A, Skerfving S. An assessment of neck and upper extremity disorders by questionnaire and clinical examination. Ergonomics. 1994;37:891-7.

16. Nordander C, Ohlsson K, Balogh I, Hansson GA, Axmon A, Persson R, et al. Gender differences in workers with identical repetitive industrial tasks: exposure and musculoskeletal disorders. Int Arch Occup Environ Health. 2008;81:939-47.

17. Sluiter JK, Rest KM, Frings-Dresen MHW. Criteria document for evaluating the work-relatedness of upper-extremity musculoskeletal disorders. Scand J Work Environ Health. 2001;27 suppl 1:1-102.

18. Kristensen TS, Hannerz H, Høgh A, Borg V. The Copenhagen Psychosocial Questionnaire-a tool for the assessment and improvement of the psychosocial work environment. Scand J Work Environ Health. 2005;31(6):438-49.

19. Bergman S, Herrström P, Högström K, Petersson IF, Svensson B, Jacobsson LTH. Chronic musculoskeletal pain, prevalence rates, and sociodemographic associations in a Swedish population study. J Rheumatol. 2001;28:1369-77.

20. Nordander C. Work-related musculoskeletal disorders-exposure assessment and gender aspects [dissertation]. Lund (Sweden): University of Lund; 2004.

21. Hansson G-Å, Balogh I, Ohlsson K, Granqvist L, Nordander C, Arvidsson I, et al. Physical workload in various types of work; part I: wrist and forearm. Int J Ind Ergon. In press.

22. Søgaard K, Sjøgaard G, Finsen L, Olsen HB, Christensen H. Motor unit activity during stereotyped finger tasks and computer mouse work. J Electromyogr Kinesiol. 2001;11:197-206.

23. Jensen C, Borg V, Finsen L, Hansen K, Juul-Kristensen B, Christensen H. Job demands, muscle activity and musculoskeletal symptoms in relation to work with the computer mouse. Scand J Work Environ Health. 1998;24(5):418-24.

24. Funch Lassen C, Mikkelsen S, Kryger AI, Brandt LPA, Overgaard E, Frølund Thomsen J, et al. Elbow and wrist/hand symptoms among 6943 computer operators: a 1-year follow-up study (the NUDATA Study). Am J Ind Med. 2004;46:521-33.

25. Forsman M, Taoda K, Thorn S, Zhang Q. Motor-unit recruitment during long-term isometric and wrist motion contractions: a study concerning muscular pain development in computer operators. Int J Ind Ergon. 2002;30:237-50.

Received for publication: 5 February 2008 